\title{
Defining Political Will
}

\section{Authors: Lori A. Post, Amber N. W. Raile, and Eric D. Raile}

This is the peer reviewed version of the following article: citation below, which has been published in final form at http://dx.doi.org/10.1111/j.1747-1346.2010.00253.x. This article may be used for non-commercial purposes in accordance with Wiley Terms and Conditions for SelfArchiving.

Post, Lori Ann, Amber N. W. Raile, and Eric D. Raile. "Defining Political Will." Politics \& Policy 38, no. 4 (August 25, 2010): 653-676. doi:10.1111/j.1747-1346.2010.00253.x.

Made available through Montana State University's $\underline{\text { ScholarWorks }}$ scholarworks. montana.edu 


\title{
Defining Political Will
}

\section{LORI ANN POST}

Yale University

AMBER N. W. RAILE

North Dakota State University

ERIC D. RAILE

North Dakota State University

\begin{abstract}
Although frequently invoked as a rhetorical tool in political discussions, "political will" remains ambiguous as a concept. Acknowledging the centrality of political will to policy outcomes, the authors propose a pragmatic and systematic approach to definition. This approach facilitates analysis by identifying particular shortcomings in political will. This identification in turn permits the application of appropriate theoretical frameworks from various disciplines and the effective construction and use of ameliorative measures. The authors also address fundamental issues like the specification of contexts. The analytical approach includes a conceptual definition dissected into essential components, along with corresponding means of operationalization and targets for assessment. Among the major definitional components are requirements that a sufficient set of decision makers intends to support a particular initiative and that such support is committed. The latter condition is difficult to ascertain, but various signals, influences, and constraints on action are observable.
\end{abstract}


An oft-cited culprit when government does not take action is a lack of political will. Over a decade ago Hammergren $(1998,12)$ characterized political will as "the slipperiest concept in the policy lexicon," calling it "the sina qua non of policy success which is never defined except by its absence." Since Hammergren's assertion, the term has enjoyed a surge in popularity, with the ambiguity of "political will" making it ideal for achieving political aims and for labeling political failures when the diagnosis is unclear. Interest groups are fond of invoking the term to account for a lack of policy change, and political campaigns across the ideological spectrum have decided that "political will" is a cornerstone of a good sound bite. Accordingly, the term has crept into the news media's coverage of the political world as well. ${ }^{1}$

The way the term "political will" is bandied about is a reflection of its presumed centrality in achieving policy change, but such casual usage is troublesome for those concerned with crafting, promoting, implementing, and analyzing public policies. We believe the concept of political will is too important to abandon to the realm of hollow political rhetoric. That would be an unfortunate fate for a concept standing at the crossroads of politics and policy and implicating the most political parts of the policy process like issue framing, agenda setting, and persuasion.

We further believe that a pragmatic, systematic definitional approach focused on outcomes could be productive in making political will an empirically useful and actionable concept. The overarching goal is to create a reliable method for identifying precise shortcomings in political will, thereby permitting

\footnotetext{
${ }^{1}$ Evidence of the proliferation of the term is not hard to find. A quick Google search for the term "political will" generates over 2.5 million hits. President Obama of the United States has used the term frequently in public speeches with regard to topics ranging from health-care reform to more efficient energy use. The United Nations has used the term recently with regard to climate change, among other topics.
} 
the application of appropriate theoretical frameworks and the selection of appropriate tactics to build political will for effective public policies. More specifically, we engineer the analytical approach so as to facilitate the application of targeted, practical solutions to problems of political will. This approach is not a causal theory of the policy-making process but rather is a tool to make possible solid measurement and observation-based analysis. While not a theory of the policy-making process itself, this tool should point researchers and practitioners to certain aspects of preexisting theories of the policy-making process (see overviews in Grindle and Thomas 1991; Sabatier 2007; Schlager and Blomquist 1996).

The definitional structure also points toward theoretical frameworks from disciplines beyond political science and policy studies, which is crucial when dealing with a complex concept like political will. Specific deficiencies in political will and corresponding solutions take many forms. Obstacles may lie in the common understanding of problems or proposed solutions, primarily the domain of communication. Sometimes blame falls to inappropriate incentives or disincentives, traditionally the concern of economists. At other times, obstacles may originate in political or social institutions or in aspects of human behavior - thereby involving political science, sociology, and psychology. Like many policy matters, our understanding of political will improves dramatically if we adopt a view that incorporates the totality of the social and behavioral sciences.

We intend to make a number of specific contributions to the study of political will, beyond the stimulation of productive debate. We raise and address some of the fundamental questions inherent in this exercise, including consideration of the ways that various contexts condition the analysis of political will. We also offer a concise yet comprehensive definition of political will that takes advantage of conceptual overlap in a sparse and disconnected literature. We then further elaborate on the essential definitional components of political will, including guidelines for operationalization and assessment targets. This elaboration of components permits identification of specific reasons for shortfalls in political will and the application of appropriate theoretical frameworks. After a brief case study of health-care reform in the United States, we conclude with contemplation of next steps.

\section{Fundamental Questions}

Prerequisite to constructing a definitional structure for analyzing political will is addressing a number of questions about its fundamental nature. One such question concerns whether political will is a binary or a continuous concept, a debate also seen in the literature on democracy (Bollen and Jackman 1989; Elkins 2000; Przeworski et al. 2000). Political will, perhaps like democracy, has both binary and continuous properties. Often political will is or is not "large" enough to achieve a particular binary outcome, such as passage and 
implementation of a specific public policy. However, certain underlying conditions, many with more continuous measurement properties, determine whether a situation crosses such a binary outcome threshold.

Another key question is whether political will is an individual-level or group-level concept. In discussing the concept with others, we have found that some people initially view political will as an individual-level concept roughly meaning individual commitment to a particular preference that happens to relate to politics or government. This viewpoint equates political will with individual preferences and likely stems from common usage of the word "will," which typically appears in the form of individual "willpower" or "free will." We argue against an approach that equates political will with individual volition. The primary reason for caring about political will is that we are concerned about political and policy outcomes. The "polis" (the ancient Greek city-state foundation of the word "political") is a social collective, and "political" will involves aggregating preferences in such a way that is meaningful for outcomes in political processes. According to this view, my singular personal preferences with regard to political issues and my personal willingness to act do not constitute "political" will unless I am a totalitarian dictator and can effectively force my preferences on an entire jurisdiction.

Yet another central question involves whether the concept of political will should incorporate issues of capacity. In other words, is consideration of complexly aggregated preferences sufficient, or must political will also consider whether a jurisdiction has the ability and resources to implement an outcome? We argue that an analytically useful, outcome-based concept must incorporate capacity. Otherwise, as we later discuss, any number of political ploys could be deciphered incorrectly as contributing to political will.

Further, global interest in political will sometimes converges on the most unstable of political regimes and situations. Is it possible to analyze these situations in a systematic and effective manner? While the uncertainty inherent in such conditions poses obstacles for assessment, we build our definition and analytical structure at all times cognizant of applicability to unstable regimes and the possible limitations of such analysis.

Finally, some may question whether political will is a universal concept. We argue that development of a general methodology is possible but that the analysis of political will is highly dependent on contexts. Political will varies across problems, solutions, places, and times. Therefore, appropriate specification of contexts is a necessary precursor to any analysis of political will. We may observe correlated support across issues because of the pooling forces of political partisanship and ideology, but the level of support for any single policy initiative depends on specific understandings of the problem and potential solutions. Since political will involves a complex aggregation of preferences, we also see variance in political will across places because of differences in people, institutions, local norms, and others. Specification of the geographic context (i.e., place) is also essential because governance stability 
varies widely across jurisdictions. A stable sociopolitical environment typically is the result of a clear structure of legitimate political authority; less stable environments rarely enjoy such clarity. Further, political will is dynamic; support for a particular initiative can, and often does, change over time.

\section{Building a Definition}

\section{Categories in the Literature}

Rather than deal with the more complex topic of political will directly, researchers and practitioners typically have focused on particular aspects of government willingness, engagement, or capacity. However, the literature is not entirely bereft of attempts to get a better handle on political will as a concept; a few articles and reports inform our exercise of building a definition for political will (see Table 1). We limit our focus here to more specific attempts in the literature to delineate what political will is.

While Hammergren (1998) ultimately speaks in terms of the likelihood of reform rather than political will, the factors she identifies as important are also significant for political will. Similarly, Andrews (2004) does not use the term but rather discusses the factors that create a "reform space." The other authors in Table 1 engage with the definitional issue more directly, although typically with a particular issue area in mind.

Brinkerhoff's (2000) framework for assessment overlaps with our approach in certain places, including an outcome-based focus and recognition of certain contexts or "environmental factors." However, Brinkerhoff's work, which is primarily directed toward political will for anticorruption reforms, differs in a

\section{Table 1. Previous Definitions of Political Will (in Chronological Order)}

Author(s)

Hammergren (1998)

Kpundeh $(1998,92)$

Brinkerhoff and Kulibaba (1999, 3); Brinkerhoff $(2000,242)$

Andrews (2004)

Anderson et al. (2005)

Rose and Greeley $(2006,5)$
Definition or Approach

Likelihood of reform.

"[D]emonstrated credible intent of political actors (elected or appointed leaders, civil society watchdogs, stakeholder groups, etc.) to attack perceived causes or effects ... at a systematic level."

"[C]ommitment of actors to undertake actions to achieve a set of objectives .... and to sustain the costs of those actions over time."

Reform space $=$ intersection of ability, authority, and acceptance.

Willingness as evidenced by commitment and inclusiveness.

"[S] ustained commitment of politicians and administrators to invest political resources to achieve specific objectives." 
number of consequential ways. Rather than beginning by defining political will and specifying its conceptual components, Brinkerhoff starts by identifying particular variable values (e.g., the application of credible sanctions) that serve as "characteristics" of political will. We believe that our sequence, which proceeds from careful definition to operationalization to measurement and assessment considerations, provides simpler and more coherent linkages among pieces. We have developed a definitional structure with the express purpose of being able to identify appropriate tactics for generating political will in a practical manner, with the flexibility for adaptation across a range of issue areas. Our approach also takes advantage of recent theoretical advancements and incorporates communication and agenda-building aspects of political will as part of an effort to integrate theoretical perspectives from multiple disciplines.

As is evident from Table 1, previous authors have recognized that political will is a complex, multifaceted concept composed of various subconcepts. These subconcepts appear to coalesce into three categories. The first category is the distribution of preferences with regard to the outcome of interest. The preferences of political elites (Hammergren 1998) are particularly important. We must also ask whether other key politicians and implementers outside the reforming coalition would accept the policies (Andrews 2004). Some authors emphasize that these preferences pertain to a particular goal or a specific objective (Anderson et al. 2005; Rose and Greeley 2006).

The second common category is the authority, capacity, and legitimacy of key decision makers or reformers. Political will is inextricably tied to policy outcomes, and the general thrust of the argument here is that political power and other resources (Brinkerhoff 2000; Brinkerhoff and Kulibaba 1999; Hammergren 1998; Kpundeh 1998) are essential for producing these outcomes. Policies backed by resource-poor coalitions suffer a deficit of political will. From the implementation side, Andrews (2004) similarly mentions organizational capacity and discretion as necessary components for policy reform.

The third category-perhaps the most difficult to quantify but nonetheless crucial - is commitment to preferences. Weakly held (thereby easily disregarded) or insincere preferences in favor of reform also detract from political will. Hammergren (1998) talks simply about how strongly elites hold their position, but other authors discuss signals of commitment, such as the allocation of analytical efforts and other resources (Brinkerhoff 2000; Brinkerhoff and Kulibaba 1999; Rose and Greeley 2006), whether reformers have devised a credible strategy for reaching the goal (Anderson et al. 2005), or willingness to apply effective sanctions for policy violations (Brinkerhoff 2000; Brinkerhoff and Kulibaba 1999). Another approach for assessing the strength and commitment of preferences is to evaluate the incentives and disincentives facing decision makers for adopting a particular position (Andrews 2004; Kpundeh 
1998). The identities and resources of probable opponents (Hammergren 1998) are examples of prominent disincentives.

\section{Basic Definitional Components}

We begin with a rough, concise form of our definition that benefits from conceptual overlap in earlier work and that acknowledges the more continuous measurement properties of the concept. Plainly speaking, political will is the extent of committed support among key decision makers for a particular policy solution to a particular problem. The consideration of the "extent" of support for a "particular policy solution to a particular problem" acknowledges the distribution of specific preferences, one of the three common categories identified in the previous section. Similarly, the use of "key decision makers" incorporates the authority, capacity, and legitimacy of the decision makers - the second common category. Finally, the use of "committed support" in the definition addresses the third category of commitment to preferences. No previous definition of which we are aware has comprehensively integrated all three categories from the literature as this definition does.

With the concise definition serving as a benchmark, we commence building a more detailed definition of political will-one that facilitates operationalization of the concept and that allows direct mapping to outcomes and the identification of specific shortcomings. Taken as a whole, this definition recognizes the binary nature of the concept through its specification of a "sufficient" set of decision makers. However, the underlying components in the definition may take on continuous measurement properties. This detailed definition of political will breaks the concept down into four components or subconceptual areas:

1. A sufficient set of decision makers

2. With a common understanding of a particular problem on the formal agenda

3. Is committed to supporting

4. A commonly perceived, potentially effective policy solution.

While successful implementation of a policy initiative may be post hoc evidence that political will existed at some prior point, our definition remains intentional because "willingness" - as inclination, disposition, or preparationis intentional. Extending the definition to action would defy this understanding of the word "will." Further, the definition allows for dynamism. The existence of political will and the range of feasible policy options are both subject to change for any given issue.

The importance of capacity also becomes evident as we address each of the individual definitional components. Components 3 and 4 directly incorporate issues of capacity, while component 1 represents a type of political capacity in itself. Again, we view capacity as an integral part of political will, in addition to preferences, intentions, and understandings. 


\section{Component 1. Sufficient Set of Decision Makers}

The first major component of the conceptual definition is that a sufficient set of decision makers (i.e., a combination of decision makers implying success) intends to support the policy. Given the political institutions of a jurisdiction, we need to identify which decision makers must refrain from blocking the initiative and its implementation as well as actors who must provide positive assent for a successful outcome (see Table 2 for operationalization considerations).

With the designation of "decision makers" we mean to limit consideration to those individuals or groups capable of approving, implementing, and enforcing public policies in a geographic area. Under more stable governance

\section{Table 2. Analyzing Political Will}

Definition Component Operationalization

(1) Sufficient set of decision makers

(2) With a common understanding of a particular problem on the formal agenda

(3) Is committed to supporting

(4) A commonly perceived, potentially effective policy solution

(b) Avoidance of ineffectiveness;
Sets of actors capable of approving, implementing, and enforcing public policies

(a) Use of similar frame and terminology;

(b) Status as "problem" on formal agenda.

Distribution and strength of specific decision-maker preferences
Assessment Targets

- Institutions and factions.

(a) Commonality and convergence in statements of decision makers with regard to problem;

(b) Importance and prominence of decision makers discussing problem; volume of discussion.

- Incentives and disincentives for political actors (institutional, electoral, and others);

- Allocation of analytical resources;

- Credibility and obligation of statements (based on reputational costs);

- Positions of key constituencies (domestic and international) and accountability relationships;

- Bargaining mechanisms;

- Cultural characteristics and constraints.

(a) Commonality and convergence in statements of decision makers with regard to proposed solution; known sources of

(c) Capacity for policy effectiveness. (b) Nonuse of short-term "fixes," knowingly ineffective policies, and diversionary tactics;

(c) Funding commitment;

(d) Inclusion of potentially effective sanctions and enforcement mechanisms;

(e) Implementation resources and support of implementers. 
conditions, decision makers will be officials within the governmental regime. Although many nongovernmental actors like interest groups and policy entrepreneurs are influential in securing political will, such actors are not the ones ultimately making and enforcing decisions. "Veto players" theory (Tsebelis 2002) provides a useful approach for thinking about potential blocking actors and the sources of positive assent when the bases of government authority are clear. Veto players theory proposes that a crucial element in understanding policy change is determining the players whose agreement or indifference is necessary to change the status quo policy position.

A broad distinction we make in applying the idea of veto players is between democratic regimes and authoritarian ones. At one extreme is an autocratic state in which the autocrat has control over the military and, consequently, control over other political actors and over the populace through the use of fear and intimidation (e.g., Saddam Hussein's Iraq). In this case, political will is virtually the intention of the autocrat. However, even in most nondemocratic regimes significant policy change requires the approval, or at least the acquiescence, of multiple political actors. Stable nondemocratic regimes sometimes require consideration of a broader notion of "decision makers," since military or religious authorities may have substantial policymaking and enforcement power. Such actors technically reside outside the official policy-making framework, but they can apply pressure or serve as threats that severely constrain the official policy makers and implementers. The lack of transparency and the disregard for the rule of law that characterize many nondemocratic regimes can also obscure the identities of the potential policy blockers and the identities of decision makers who could contribute to a sufficient set for policy passage and implementation. These characteristics of nondemocratic regimes reinforce the need for strong contextual knowledge in analyzing political will.

In more democratic regimes, the number of veto players depends on the configuration of formal and informal political institutions. Law-making powers may be shared (i.e., presidential system), may be fused (i.e., parliamentary system), or may take a hybrid form (i.e., presidential-parliamentary system). Federal and confederal regimes can also increase the number of veto players, since power is shared among different levels of government. The extent of judicial independence and powers determines whether the judiciary serves as a potential obstacle. Veto players may also exist within institutions, as is sometimes the case with leadership, committees, or bicameral chambers within a legislature. Furthermore, key bureaucratic actors often become veto players because of their role in implementing policies and making "street-level" policies.

The political party system (e.g., single-party system, two-party system, multiparty system) also contributes to the number of veto players. In presidential systems, different political parties may control the legislature and executive (i.e., divided government), potentially enhancing the blocking role of the parties. The sizes of the parties are also important, although small parties 
can have substantial influence if their support is necessary to form a coalition government or to maintain a minority government.

Under less stable governance conditions, more work may be necessary to identify which actors, if any, have the requisite power. Competing factions often claim they alone can implement and enforce policies under such conditions. For example, despite Somalia's recent creation of a transitional parliamentary government, the U.S. Central Intelligence Agency still designates the country as having "no permanent national government." The country remains split into areas controlled by the Transitional Federal Government, Islamic fundamentalists, and Somaliland separatists - among other divisions. Implementation and enforcement of any policy uniformly throughout the entire country is not realistic under current conditions. Further consideration of political will would require movement below the national level or creation of countrywide stability in such a way that "sufficient" coalitions could emerge.

\section{Component 2. Common Understanding of a Particular Problem on the Formal Agenda}

The second major definitional component is a common understanding of a particular problem on the formal agenda. In other words, the decision makers agree that a particular issue or condition has reached problem status, agree on the nature of the problem, and agree that the problem requires government action. Creating sufficient support for a particular policy solution is typically quite difficult absent this common understanding; the intentions of decision makers to address a problem can not create an aggregate political will if aimed at different problems.

An issue or condition becomes a "problem" when there is a belief that government must take action in relatively short order (Kingdon 2003). At this juncture, an issue also typically obtains a place on the "formal agenda" or the "list of items which decision makers have formally accepted for serious consideration" (Cobb, Ross, and Ross 1976, 126). Although achieving a spot on the formal agenda is a key piece of the policy-making process, decision makers must move quickly because the often-related "public agenda," or the list of items to which the general public is paying attention, has a limited "carrying capacity" (McCombs and Zhu 1995). Many problems, especially certain types of social problems, appear on and disappear from the public agenda rapidly (Downs 1972). As a consequence, any policy-making effort that requires citizen attention must take into account the interaction between the public agenda and the formal agenda. Of course, the formal agenda may be quite informal in unstable governance situations. However, our definition's reliance on the preferences of "decision makers" keeps the focus on potential agenda setters, who typically exist even under unstable circumstances.

Effectively addressing a problem on the formal agenda also requires a common frame of reference or understanding of the problem. Fundamentally 
different views of a problem suggest fundamentally different solutions. The activity of "issue definition" is a driving force in the policy-making process (Baumgartner and Jones 1993). Problems often get stuck at this stage as dueling interpretations compete for supremacy. Political elites frequently engage in "heresthetical maneuvers" (Riker 1986) or "frame" issues (Druckman 2001) in such ways that particular dimensions and interpretations become most salient. Is the U.S. prison in Guantanamo Bay a response to a terrorist problem, or is it a human rights problem? Is abortion a problem of government interfering with individual rights or a problem of protecting life? Clearly, the dominance of one frame prejudices the range of possible solutions. As another example, the Medicare (old-age health insurance) program in the United States has long languished off the formal agenda despite serious projected shortfalls in funding (Boards of Trustees 2009, 12). One important reason for this languishing is that politicians, with their short-term incentive structures, have seen Medicare more as an electoral problem (whether they increase taxes and decrease benefits or try to regulate escalating health-care costs) than a policy problem. The frame of reference of the key decision makers, then, is written in an entirely different language than is the policy problem.

In terms of operationalization, how does one know that decision makers have converged on a commonly defined "problem?" Here, actual discussion of the problem is likely to provide the clearest indication. Influential decision makers will publicly discuss the problematic elements of an issue and will use similar terminology and frames when doing so (see the communication-based assessment targets for this component in Table 2). Competition among differing problem interpretations will quiet. The formation of a large political coalition around a single problem definition is perhaps the clearest signal.

\section{Component 3. Commitment to Support}

The third component is that a sufficient set of decision makers is committed to supporting a particular policy. This component lies at the core of political will but is the most problematic to ascertain - a complication that likely has prevented greater elaboration of political will as a concept. How do you determine the preferences of decision makers and the intention to act on those preferences? As importantly, how do you know if these intentions are genuine or strong?

While divining actual intent is often impossible, indirect signals of intent and influences on intent are observable. Some of these signals and influences were mentioned earlier, including the allocation of analytical efforts and other resources, willingness to apply effective sanctions, and the incentives and disincentives facing decision makers for adopting a particular position. We would add to this list a number of items.

One indication of commitment appears when decision makers make credible, binding statements or undertake actions of a similar nature. Game 
theorists talk about the reputational costs associated with advocating one choice and then later switching to a different option. These reputational costs are one of the consequences of bargaining in front of an audience like the general public. A situation involving high reputational costs (e.g., a high attention problem) can make the statements of decision makers more credible and more constraining. The other assessment targets listed in Table 2 for this component seem applicable to the narrower assessment of statement credibility and constraint as well.

The sources of pressure weighing on decision makers are other signals of intent. Who are a decision maker's key constituents? What position do they advocate? How much leverage do they have over the decision maker? The answers to these questions provide solid clues as to a decision maker's intentions, sometimes even more reliably than do direct statements.

Therefore, the accountability relationships between decision makers and their constituencies are an important element in determining intent. The accountability mechanisms that characterize representative democratic regimes - particularly regular, free, and fair elections - tend to build linkages between public opinion and political will. These linkages are not perfect largely because of informational problems (i.e., not all constituents know what they want or communicate those desires) and because of nonuniformity in constituency pressures (i.e., not all constituents want the same thing). However, the accountability mechanisms facilitate a bottom-up convergence of public opinion and political will, which is very different from the top-down "convergence" sometimes observed in authoritarian regimes.

The electorate is not the only type of constituency with influence over decision makers, however. Organizations and the business community can serve as important constituents, as can potential employers, bribers, blackmailers, special interests that fund political campaigns, and others. The more negative motivators among these often remain hidden; other powerful forces that can constrain and punish political actors, like the military and religious authorities mentioned earlier, may be more conspicuous. Pressure on a decision maker can come from external sources as well. The era of globalization and supranational institutions has increased these pressures for both the developed and developing worlds. However, these pressures are perhaps most intense in the developing world, where donor countries, international governance organizations, transnational corporations, and international nongovernmental organizations may have substantial influence on the activities of government. The preferences of these external "constituencies" can be strong influences on political will within a country.

Institutional incentive structures and bargaining mechanisms within a government also influence intent. For example, is it possible to determine whether taking a specific position would be harmful or helpful to career prospects for political actors within the institutional framework? Strong political parties with disciplined members and strong leadership ease the job of discerning intent. As 
concerns bargaining mechanisms, is there a strong pattern of "logrolling" (i.e., intertemporal trading of policy votes) or of pork-barrel politics (i.e., funding for geographic-specific projects in exchange for policy votes)? If so, one may discover clues about intent from such patterns. Additionally, we can examine the types of goods controlled by particular political actors. For instance, how freely may the executive dole out cabinet posts or lower-level political jobs? If an executive controls substantial resources for trade, the likelihood of an executive building sufficient support becomes greater.

Finally, cultural characteristics and constraints may provide clues about the intentions of decision makers. For example, cultures exhibit different tolerances for uncertainty and ambiguity (Hofstede and Hofstede 2005). Policy makers may face more backlash for substantial policy changes in countries with high "uncertainty avoidance." Additionally, some cultures place a greater emphasis on decision making by consensus than do others. In countries with more consensual cultures, items may be less likely to appear on the formal agenda in the first place if they do not have the true intended support of many or all the necessary political actors. Norms related to manipulation and reputational costs also seem relevant. Intention may be easier to discern if tolerance for manipulation is low or if the importance of saving face is high.

\section{Component 4. A Commonly Perceived, Potentially Effective Policy Solution}

The fourth and final component is that support is aimed at a commonly perceived, potentially effective policy solution. The initial part of this component is that the sufficient set of decision makers supports the same general policy to address the commonly understood problem. This is not to say that all relevant decision makers will agree completely on the details but rather that they share a perception about the type of policy outcome necessary. Without including common perception of the solution in the definition, we would not necessarily be talking about a singular, aggregate political will; instead, we could be talking about multiple different, noncohesive preference sets.

The social security program in the United States provides an example, although many other countries face similar pension system problems. Political actors have largely agreed on the existence and general nature of a problem - a future funding shortfall-although views of the extent of the problem range from the rather severe (see the $\$ 5.3$ trillion long-range shortfall in Board of Trustees 2009, 60) to the relatively benign (e.g., Krugman 2004). Former Republican President Bush famously said in the 2005 State of the Union Address that the system faced "bankruptcy," while prominent Democrats on fiscal and monetary matters like Senator Kent Conrad frequently have referred to the situation as "unsustainable."

The issue of solutions is far more complicated. A commonly cited source of the problem is a shifting age population structure and the impending retirement of the large "baby boomer" generation, but no feasible policy solutions directly 
address this issue. A common conservative proposal is the privatization or semiprivatization of social security accounts. President Bush faced a good deal of opposition and indifference when he promoted the idea of private-sector investment around the country (Baker 2005). Many political actors and citizens have not seen privatization as a viable solution, and for some, the battering taken by the stock market in 2008 provided an even stronger counterargument (e.g., Spitzer 2009).

While some support for privatization remains (e.g., see Tanner 2010), others have advocated for a combination of increasing taxes and decreasing benefits as a numerically feasible solution (e.g., Diamond and Orszag 2005). Such a solution is not feasible from an electoral perspective for either party, however. Consequently, two nonviable "solutions" have competed weakly for public attention, and no substantial action is currently on the horizon.

The trickier part of the final component of political will is the requirement that the proposed policy solution be potentially effective. Our emphasis lies more with looking for behavior that undermines political will rather than predicting whether a policy truly will be "effective" by certain evaluative standards. Inclusion of this component also permits us to set apart political will produced by manipulation and coercion, since this type of political will often is short lived. One could remove this "effectiveness" clause from the definition without wholly eviscerating it, but we feel that our outcome-based focus makes the clause important.

Political actors frequently support policies that are known short-term "fixes," especially when the political actors have short-term horizons themselves (e.g., frequent elections) or are dealing with constituencies with rather short memories. Downs' (1972) issue-attention cycle proposes that many social policies fit this profile. People eventually feel satisfied that at least something has been done, or attention wanes when people realize what sacrifices would be necessary to implement a long-term solution. Another frequently occurring situation involves political actors agreeing to policies of compromise that are possible because of overlapping preferences, knowing that the implemented policy will not really address the problem. Again, political actors often receive positive credit for such policies. Going back to the social security example, political actors in the United States in recent decades have responded to this problem with short-term bandages. The age at which a beneficiary begins drawing checks from the system has been increased slightly (via the Social Security Amendments of 1983). While marginally helpful and politically feasible because the costs are incurred well in the future, this policy change has not fully dealt with the underlying structural problems.

Another popular strategy is to divert public attention or to "fix" a problem by firing (or occasionally executing in the case of a country like China) a scapegoat public official when a negative event comes to the public's attention. While such firings are sometimes necessary parts of a potentially effective solution, they do not fix underlying systematic issues. As a consequence, such 
actions do not constitute evidence of political will if they are not accompanied by other potentially effective measures. A final negative example is for a government to study an issue "to death," simultaneously providing the illusion of action and preventing real movement on the issue.

In the way of a more positive example, the U.S. Congress a couple of decades ago adopted a way to overcome a problem with solution stalemates and the implementation of short-term nonsolutions. At issue was the closing of expensive, surplus military bases in the United States (the commonly recognized problem), but each base closing threatened to decimate a local economy. Consequently, political representatives for the local areas would find ways to block action. In response, the Congress in the late 1980s created a bipartisan commission that would study the issue and report on a list of bases to be closed. The president could only approve or disapprove of the entire set of recommendations, and Congress could only stop the process by halting action on the entire list. This preapproved procedure thereby overcame problems associated with considering each base individually and allowed for a potentially effective outcome. Although other factors also facilitated movement on this issue, the decision-making procedure was a key (Mayer 1995).

The issue of potential policy effectiveness also ties back closely to intent. Can we say that political actors really intend to support a particular policy if they plan to undermine that policy in some way? Political actors may support a policy initiative with the understanding that backlash or intransigence eventually will derail the initiative or detract from its effectiveness. Laws lose their meaning if they are widely disregarded and fair enforcement becomes impossible.

Another popular method of intentionally undermining an initiative is to approve a policy without adequately funding the program. For example, governments around the world frequently do not give public anticorruption organizations sufficient resources or powers to fight corruption. Campaign finance reforms often lack bite as well. In both examples the existing power players could incur substantial costs if policies were implemented effectively.

Inadequate bureaucratic capacity, similar to Andrews' (2004) "ability" factor, can also undermine a policy. Implementing a new policy program often requires new administrative resources and personnel. Just as vital is the support of implementers, especially in jurisdictions with high bureaucratic discretion. Research on "bottom-up" policy implementation (Hill and Hupe 2002) emphasizes the power of bureaucrats to make new policy or to sabotage initiatives. Legislators or executives who anticipate significant bureaucratic resistance and do nothing to constrain or placate key bureaucratic actors may be intentionally undermining a policy initiative.

One step in terms of operationalization, then, is assessing convergence on a commonly perceived solution. Analysis here would parallel assessment of a commonly perceived problem. Is there evidence of a common frame and common language for the solution? A second step is assessing whether key political actors 
are intentionally trying to implement a nonsolution or to undermine a policy by denying appropriate capacity for its success. Again, including capacity in the definition may be controversial, but we should at least account for the appearance of "false" political will manipulated by key political actors.

\section{Health-Care Reform in the United States}

We offer here a brief application of our definitional approach to the issue of health-care reform in the United States. The purpose of this case study is to demonstrate the utility of the definitional approach in zeroing in on specific shortcomings in political will and to illustrate the potentially dynamic nature of political will. Of course, this topic is a complex one deserving much fuller treatment, and the issue area remains subject to some volatility at the time of this writing.

Although individual states have been free to introduce reforms, the healthcare industry has long avoided greater governmental involvement at the national level. The application of our definitional structure begins with a "sufficient set of decision makers" at this national level. Applying the definition makes immediately clear that this sufficient set can be a moving target. The passage of nationwide policy would require the assent of a simple majority of both houses of Congress and of the president. Also important, however, is that the rules of the Senate allow for unlimited debate, thus preventing a vote unless 60 senators vote to halt that debate.

Those 60 votes needed to invoke cloture took on a prominent role in the debate and loomed as an obstacle for political will. Simple counting of partisan seats in the Senate oversimplifies matters, even if partisan voting unity has increased in the United States over the last few decades (Maisel and Brewer 2010, 403). Nevertheless, the changeover of a Massachusetts seat from Democratic to Republican control via special election, thus removing the filibuster-proof majority, complicated the process of squaring House and Senate versions of the health-care reform legislation (Cooper 2010). In response, some congressional Democrats promoted the ideas of using "budget reconciliation" to circumvent a Republican filibuster on a new vote in the Senate or of having the House pass or "deem and pass" the Senate version of the bill as ways of achieving "sufficient" support (Montgomery and Kane 2010; Rovner 2010). The House eventually passed the Senate version of the bill, but doing so required companion legislation passed by reconciliation in the Senate to "fix" certain provisions; furthermore, Democrats still had to fight off various procedural attempts by Republicans in Congress to derail the legislation (Barrett et al. 2010).

The "common understanding of a particular problem on the formal agenda," the second definitional component of political will, centered on the linked problems of health-care services and health-care insurance being prohibitively expensive for a large segment of the U.S. population. Consequentially, an estimated 46 million Americans do not have health-care 
insurance (U.S. Census Bureau 2009), and health-care providers often must absorb and pass along the costs of unpaid medical bills. After an appearance during the early 1990s under the Clinton Administration, health-care reform largely disappeared from the formal agenda. The most recent major activity in this issue area was the extension of Medicare benefits to cover prescription drug costs in 2003 (i.e., the Medicare Prescription Drug, Improvement, and Modernization Act), a move that did little to address the problem cited here.

The place of this issue on the formal agenda throughout 2009 and early 2010 was one tenuously held for a number of reasons. Republicans had preferred to stall on the issue until after the 2010 elections, and the Democrats' loss of a filibuster-proof majority in the Senate only strengthened such plans. The tenuous place on the formal agenda was also related to our third definitional component of political will, "commitment to support." That commitment wavered on the part of some political actors because of an intense counteroffensive from strongly committed and entrenched minorities with intense preferences and clear interests, with the private health-care industry serving as the most prominent such minority. Support for the reform proposals eroded over the courses of months of debate (Pallarito 2010), perhaps largely because of the concerted effort on the part of health insurers to sway public and political opinion. Democratic legislators from mostly conservative states in particular began to incur political costs for supporting the reform legislation as the 2010 elections approached.

Our fourth definitional component for political will is "a commonly perceived, potentially effective policy solution." The proposals appeared to pass our test of potential effectiveness in the respect that no significant attempts to pass clearly ineffective legislation were evident. However, the common perception of a solution became more problematic as the support of a greater number of Republicans and constituency-constrained moderate Democrats became necessary. Early conflict largely focused on the "public option" in the original House version of the legislation, which called for a government-run insurance option that would compete with private insurers to lower premium prices - a provision particularly bothersome to private insurers. The attack (Potter 2009) on this provision spurred broader questions about the appropriate role of government in the marketplace, and claims of "Marxism," "communism," and "socialism" became frequent as forces outside the formal debate on health-care reform - most prominently the Tea Party Movementattacked the process. The White House declared the public option provision "dead" in early 2010 because of a lack of support (Allen 2010).

While some conservatives seemed mostly concerned with blocking reform, others promoted alternative solutions, such as legal reforms, that would decrease insurance premiums by reducing malpractice settlement costs as well as various measures aimed at personal responsibility and aimed at loosing free-market forces to drive down health-care costs and insurance premiums. Ultimately, the 
changing conditions mentioned earlier led to President Obama holding a bipartisan "Healthcare Summit" (Bash et al. 2010) and emphasizing Republican ideas included in the health-care reform proposal (White House 2010).

Overall, this example illustrates the dynamism of political will and the relationships among its conceptual components. Again, the approach here is designed to permit the identification of specific shortcomings in political will. The first component looks at a sufficient set of decision makers, and a challenge for political will in this case was that the sufficient set involved a supermajority and was a moving target. The second component deals with common understanding of the problem and placement on the formal agenda. The healthcare reform issue languished a bit on a rather volatile and ambitious formal agenda, although key political actors did appear to share a very basic view of the problem. The third component addresses committed support to a solution, and that commitment wavered over the course of a few crucial months. The final component deals with a commonly perceived and potentially effective policy solution. Changes in the set of sufficient decision makers, together with wavering support, made broader backing more crucial, which in turn gave greater importance to certain conservative and moderate interpretations of appropriate policy solutions. At the time of this writing, these specific shortcomings had been surmounted, although they led to moderation and any one of them could have spelled doom for the health-care reform legislation. The battle also had not concluded, as attorneys general from a number of states threatened to sue over some of the requirements in the legislation (Fabian 2010).

\section{Summary and Discussion}

Political will has been an idea riddled with ambiguity and imprecision. Political actors have many reasons to obfuscate, which makes analysis of political will difficult. Political survival also often requires labeling failures in a way that places blame on a vague and distant "other," and chalking it all up to a lack of political will fits quite nicely. Up until now evidence of political will typically has been considered indirect and retrospective - with a failure to implement change purportedly manifesting a lack of political will and successful implementation constituting proof of its existence. The complexities of political will have further contributed to the paucity of scholarly efforts aimed at a concept that is central to policy making. Convinced of the importance of political will as a concept, we have begun the development of an approach to analyze political will in a more systematic manner. Only through systematic identification of specific deficiencies can we identify appropriate theoretical frameworks from multiple disciplines to apply to the situation and subsequently work to design appropriate tactics for generating and securing political will for effective policies.

Prior to the development of the definitional structure, we addressed a number of fundamental questions about the nature of political will. We argued 
that political will has both binary and continuous measurement properties but that the concept is a group-level, complexly aggregated one. We also argued that the outcome-based focus of political will requires incorporating issues of capacity. Further, we recognized the utility of analyzing unstable governance situations and developed the definitional structure with an eye toward such situations. Beyond these fundamental questions, we noted the necessity of appropriately specifying contexts prior to analyzing political will, a step that allows generalization of the approach.

We have developed a pragmatic definition that explicitly recognizes the complexity of political will, takes advantage of conceptual overlap in the literature, and incorporates the essential components of political will. We have also provided ideas about how to operationalize and assess these components, mapping directly from the definition. We have built an operational definition of political will with four major component areas:

1. A sufficient set of decision makers

2. With a common understanding of a particular problem on the formal agenda

3. Is committed to supporting

4. A commonly perceived, potentially effective policy solution.

Table 2 lays out the definitional component areas and further specifies operations and targets for assessment. Worth reiterating is that the tools for making these assessments come from the range of social and behavioral sciences, including disciplines like political science, communication, economics, sociology, and psychology. Essentially, a sufficient set of decision makers is one whose support would lead to the passage and implementation of an initiative without the strong chance of a veto. Common understanding of the nature of the problem and the solution is critical to a successful policy outcome, while the problem must be one that decision makers are seriously considering. The meaning of "committed" support is also critical. We have supplied a list of signals and influences relevant for evaluating the intentions of political actors. Finally, by incorporating the potential effectiveness of a policy solution into our approach we mean to eliminate illusory political will and to allow the inclusion of capacity issues. True commitment to success means attempting to avoid clear capacity problems in implementation.

While communication is significant in this approach to assessing political will, it assumes even greater importance in the next major step of identifying tactics for generating political will. Social change researchers (Post, Salmon, and Raile 2008; Salmon, Post, and Christensen 2003) discuss how campaigns identify, define, and focus attention on an issue. For example, if the shortcoming in political will resides in the lack of a common problem understanding, the answer may reside in reframing causal attribution, comparison groups, or issue categorization (Kingdon 2003; Nelson 2004; Stone 2002). As another example, the news media plays a substantial role in setting agendas and influencing 
perceptions of issue importance (McCombs and Reynolds 2002). Therefore, the news media may be a pivotal consideration when the deficiency in political will is due to agenda limitations. In short, systematic assessment of political will should facilitate the development of communication campaigns to influence policy outcomes in beneficial ways, given particular contexts.

The definitional approach outlined here represents an initial step toward analyzing the difficult concept of political will and remains open to refinement. Our next steps include elaboration of the corresponding notion of "public will," along with examination of the intersection of political will and public will. Furthermore, we intend to continue refining the measurement and assessment of political will. Although the rudimentary health-care reform case study included here was illustrative in a number of ways, we look forward to more extensive and detailed empirical applications of our approach. Additionally, understanding political will requires a synthesis of diverse areas of knowledge. Political institutions, social norms, the historical context, and the informational environment are among the factors that can contribute. We therefore intend to explore how existing theoretical frameworks from political science and policy studies, as well as other social and behavioral sciences, can inform the assessment of political will, the understanding of processes influencing political will, and the design of effective tactics for generating political will. Evaluating political will can be a significant undertaking, especially in highly dynamic or low information environments; however, if public policies and change matter, so does political will.

\section{References}

Allen, Jared. 2010. "Key Dems: The Public Option Is Dead." The Hill (February 23). Accessed on April 29, 2010. Available online at http:// thehill.com/homenews/house/83153-hoyer-public-option-is-likely-dead 
Anderson, Michael, Andrew Branchflower, Magüi Moreno-Torres, and Marie Besançon. 2005. "Measuring Capacity and Willingness for Poverty Reduction in Fragile States." Poverty Reduction in Difficult Environments (PRDE) Working Paper No. 6; Department for International Development; Government of the United Kingdom (January). Accessed on April 29, 2010. Available online at http://ageconsearch.umn.edu/bitstream/12820/1/pr050006. pdf

Andrews, Matthew. 2004. "Authority, Acceptance, Ability and PerformanceBased Budgeting Reforms." International Journal of Public Sector Management 17 (4): 332-344.

Baker, Peter. 2005. "Bush Continues Social Security Campaign: Polls Show President's Roadshow Failing to Drive up Support for His Plan." Washington Post (May 20). Accessed on April 29, 2010. Available online at http://www. washingtonpost.com/wp-dyn/content/article/2005/05/19/AR2005051901617.

html

Barrett, Ted, Tom Cohen, Alan Silverleib, Lisa Desjardins, and Deirdre Walsh. 2010. "House Passes Senate's Health Care 'Fixes' Bill." CNN (March 26). Accessed on April 29, 2010. Available online at http://www.cnn.com/2010/ POLITICS/03/25/health.care.main/index.html

Bash, Dana, Ed Henry, Kristi Keck, and Deirdre Walsh. 2010. "Health Care Summit Ends without Apparent Movement Forward." CNN (February 25). Accessed on April 29, 2010. Available online at http:// www.cnn.com/2010/POLITICS/02/25/health.care.summit/index.html?iref= allsearch

Baumgartner, Frank R., and Bryan D. Jones. 1993. Agendas and Instability in American Politics. Chicago: The University of Chicago Press.

Board of Trustees of the Federal Old-Age and Survivors Insurance and Federal Disability Insurance Trust Funds (Board of Trustees). 2009. "2009 Annual Report." Accessed on April 29, 2010. Available online at http:// www.ssa.gov/OACT/TR/2009/tr09.pdf

Boards of Trustees of the Federal Hospital Insurance and Federal Supplementary Medical Insurance Trust Funds (Boards of Trustees). 2009. "2009 Annual Report.” Accessed on April 29, 2010. Available online at http://www.cms.hhs.gov/ReportsTrustFunds/downloads/tr2009.pdf

Bollen, Kenneth A., and Robert Jackman. 1989. "Democracy, Stability, and Dichotomies.” American Sociological Review 54 (4): 612-621.

Brinkerhoff, Derick W. 2000. "Assessing Political Will for Anti-Corruption Efforts: An Analytic Framework." Public Administration and Development 20 (3): 239-252. 
Brinkerhoff, Derick W., and Nicolas P. Kulibaba. 1999. "Identifying and Assessing Political Will for Anti-Corruption Efforts." USAID's Implementing Policy Change Project. Working Paper No. 13 (January). Accessed on April 29, 2010. Available online at http://www.usaid.gov/our_work/democracy_and_ governance/publications/ipc/wp-13-ms.pdf

Cobb, Roger, Jennie-Keith Ross, and Marc H. Ross. 1976. "Agenda Building as a Comparative Political Process." American Political Science Review 70 (1): 126-138.

Cooper, Michael. 2010. "G.O.P. Senate Victory Stuns Democrats.” New York Times (January 19). Accessed on April 29, 2010. Available online at http:// www.nytimes.com/2010/01/20/us/politics/20election.html

Diamond, Peter A., and Peter R. Orszag. 2005. "Saving Social Security." Journal of Economic Perspectives 19 (2): 11-32.

Downs, Anthony. 1972. "Up and Down with Ecology: The Issue-Attention Cycle." Public Interest 28 (Summer): 38-50.

Druckman, James N. 2001. "The Implications of Framing Effects for Citizen Competence." Political Behavior 23 (3): 225-256.

Elkins, Zachary. 2000. "Gradations of Democracy? Empirical Tests of Alternative Conceptualizations." American Journal of Political Science 44 (2): 293-300.

Fabian, Jordan. 2010. "Thirteen States File Lawsuit against Healthcare Bill." The Hill (March 23). Accessed on April 29, 2010. Available online at http:// thehill.com/blogs/blog-briefing-room/news/88571-thirteen-states-file-lawsuitagainst-healthcare-bill

Grindle, Merilee S., and John W. Thomas. 1991. Public Choices and Policy Change: The Political Economy of Reform in Developing Countries. Baltimore, MD: The Johns Hopkins University Press.

Hammergren, Linn. 1998. "Political Will, Constituency Building, and Public Support in Rule of Law Programs." Center for Democracy and Governance; Bureau for Global Programs, Field Support, and Research; U.S. Agency for International Development (August). Accessed on April 29, 2010. Available online at http://pdf.usaid.gov/pdf_docs/PNACD023.pdf

Hill, Michael, and Peter Hupe. 2002. Implementing Public Policy. Thousand Oaks, CA: SAGE Publications, Inc.

Hofstede, Geert, and Gert Jan Hofstede. 2005. Cultures and Organizations: Software of the Mind. 2d edition. New York: McGraw-Hill.

Kingdon, John W. 2003. Agendas, Alternatives, and Public Policies. 2d edition. New York: Addison-Wesley Educational Publishers, Inc. 
KPundeh, SAHR J. 1998. "Political Will in Fighting Corruption.” In Corruption and Integrity Improvement Initiatives in Developing Countries, edited by Sahr J. Kpundeh and Irene Hors. New York: UNDP. 91-110.

Krugman, Paul. 2004. "Inventing a Crisis." New York Times (December 7). Accessed on April 29, 2010. Available online at http://www.nytimes.com/2004/ 12/07/opinion/07krugman.html?_r=1\&scp=539\&sq=\&st=nyt

Maisel, L. Sandy, and Mark D. Brewer. 2010. Parties and Elections in America: The Electoral Process. fifth edition. Lanham, MD: Rowman \& Littlefield Publishers, Inc.

Mayer, Kenneth R. 1995. "Closing Military Bases (Finally): Solving Collective Dilemmas through Delegation.” Legislative Studies Quarterly 20 (3): 393-413.

McCombs, Maxwell, and Amy Reynolds. 2002. "News Influence on Our Pictures of the World." In Media Effects: Advances in Theory and Research, edited by Jennings Bryant and Dolf Zillmann. Mahwah, NJ: Lawrence Erlbaum Associates. 1-18.

McCombs, Maxwell, and Jian-Hua Zhu. 1995. "Capacity, Diversity, and Volatility of the Public Agenda: Trends from 1954 to 1994.” Public Opinion Quarterly 59 (4): 495-525.

Montgomery, Lori, and Paul Kane. 2010. "House May Try to Pass Senate Health-Care Bill without Voting on It." Washington Post (March 16). Accessed on April 29, 2010. Available online at http://www.washingtonpost.com/wp-dyn/ content/article/2010/03/15/AR2010031503742.html

Nelson, Thomas E. 2004. "Policy Goals, Public Rhetoric, and Political Attitudes." Journal of Politics 66 (2): 581-605.

Pallarito, Karen. 2010. "Poll Shows Eroding Support for Health Reform." U.S. News and World Report (February 11). Accessed on April 2, 2010. Available online at http://www.usnews.com/health/managing-your-healthcare/ policy/articles/2010/02/11/poll-shows-eroding-support-for-health-reform.html

Post, Lori Ann, Charles T. Salmon, and Amber N. W. Raile. 2008. "Using Public Will to Secure Political Will." In Governance Reform under Real-World Conditions: Citizens, Stakeholders, and Voice, edited by Sina Odugbemi and Thomas Jacobson. Washington, DC: The World Bank. 113-124.

Potter, Wendell. 2009. "How Insurance Firms Drive Debate." CNN (August 17). Accessed on April 29, 2010. Available online at http://www.cnn.com/2009/ POLITICS/08/17/potter.health.insurance/

Przeworski, Adam, Michael E. Alvarez, José Antonio Cheibub, and Fernando Limongi. 2000. Democracy and Development: Political Institutions and Well-Being in the World, 1950-1990. New York: Cambridge University Press. 
Riker, William H. 1986. The Art of Political Manipulation. New Haven, CT: Yale University Press.

Rose, Pauline, and Martin Greeley. 2006. "Education in Fragile States: Capturing Lessons and Identifying Good Practice." Development Cooperation Directorate; Organization for Economic Cooperation and Development (May). Accessed on April 29, 2010. Available online at http://www.ids.ac.uk/ download.cfm?objectid=F94A1EE3-5056-8171-7B7501A49B104B57

Rovner, Julie. 2010. "Health Care No Stranger to Reconciliation Process." National Public Radio (February 24). Accessed on April 29, 2010. Available online at http://www.npr.org/templates/story/story.php?storyId=124009985

Sabatier, Paul A., ed. 2007. Theories of the Policy Process. 2d edition. Boulder, CO: Westview Press.

Salmon, Charles T., Lori A. Post, and Robin E. Christensen. 2003. "Mobilizing Public Will for Social Change." Communications Consortium Media Center, Michigan State University (June). Accessed on April 29, 2010. Available online at http://www.mediaevaluationproject.org/MobilizingWill.pdf

Schlager, Edella, and William Blomquist. 1996. "A Comparison of Three Emerging Theories of the Policy Process." Political Research Quarterly 49 (3): 651-672.

Spitzer, Eliot. 2009. "Privatize Social Security?! Can We Finally Kill This Terrible Idea?" Slate (February 4). Accessed on April 29, 2010. Available online at http://www.slate.com/id/2210414

Stone, Deborah. 2002. Policy Paradox: The Art of Political Decision Making. Revised edition. New York: W. W. Norton \& Company.

Tanner, Michael D. 2010. "Social Security Private Option: The Answer to a Looming Entitlement Disaster Is Opting Out." Washington Times (January 22). Accessed on April 29, 2010. Available online at http://www. washingtontimes.com/news/2010/jan/22/social-security-private-option/

Tsebelis, George. 2002. Veto Players: How Political Institutions Work. Princeton, NJ: Princeton University Press.

U.S. Census Bureau. 2009. "Income, Poverty and Health Insurance Coverage in the United States: 2008." U.S. Census Bureau (September 10). Accessed on April 29, 2010. Available online at http://www.census.gov/prod/2009pubs/p60236.pdf

White House. 2010. "Republican Ideas Included in the President's Proposal." White House. Accessed on April 29, 2010. Available online at http:// www.whitehouse.gov/health-care-meeting/republican-ideas 